\title{
El Seguro - Hoy y Mañana
}

\author{
por Jaime Argüelles y Armada *
}

Todos los sectores de la actividad económica se encuentran actualmente en situación inestable en los países desarrollados; la profunda crisis que aqueja a la economía occidental desde hace ya mas de ocho años, crea circunstancias imprevistas que exigen tratamientos nuevos.

Como en toda época de profundo cambio, hoy se pone a prueba la imaginación de los gerentes, porque el futuro tiene que ser previsto, y del mayor o menor acierto en esta previsión depende, inevitablemente, el éxito o el fracaso. En circunstancias como las actuales no se avanza seguro poniendo el pie en las mismas huellas de nuestros antecesores. Hay que distinguir qué conceptos son inmutables por esencia y cuáles son los que se encuentran en plena evolución. Este es el gran problema con que se enfrenta hoy todo responsable de un negocio.

La vida del seguro no puede ser una excepción a esta regla general. Se encuentra, como todo, profundamente afectada por ella ; pero presenta, sin embargo, sus especiales características. Las actuales circunstancias económicas no operan, pongo por caso, de la misma forma sobre la vida de una empresa especializada en fabricar o vender electrodomésticos y la de una Compañía de Seguros. general ?

¿ Cuáles son los principales problemas con que se enfrenta hoy día el seguro en

1. Un exceso de capacidad creado en la década de los sesenta que ha coincidido en su final con la iniciación de la crisis y el consecuente estancamiento en la producción de nuevos bienes.

2. Una fuerte inestabilidad en el valor de las monedas que han soportado pérdidas cuantiosas con tipos de inflación desconocidos para el dólar, la libra, el franco suizo, el marco, etc.

3. Unos tipos de interés que, al mejorar los ingresos de las compañías por ese cauce, han permitido rebajar las primas a niveles técnicamente inaceptables.

4. Una constante modificación en las exigencias de la clientela y en la naturaleza de nuevos riesgos a cubrir, producida fundamentalmente por el progreso tecnológico y por la profunda evolución social que estamos viviendo.

$\mathrm{El}$ efecto sobre el seguro de los cuatro puntos reseñados es gravemente dislocador, produciendo los siguientes fenómenos :

* Presidente, La Union y el Fenix Español, Madrid. 
1. El exceso de capacidad determina una furiosa competencia dentro de un mercado en el que aparecen pocos nuevos capitales en riesgo ; hay poca inversión, poca creación de nuevos bienes y, por tanto, poca base para la producción de nuevos seguros en los Ramos tradicionales. Así, una buena parte de nuestra actividad competidora se emplea en arrancarnos unos a otros el seguro de los bienes que ya están asegurados desde hace años.

2. La pérdida del valor de la moneda, es decir la inflación, es otro elemento que trastorna el desempeño de la actividad aseguradora. Sus efectos son varios ; en primer lugar, produce una situación de infraseguro generalizado, ya que no es frecuente el cliente que corrige anualmente, en moneda corriente, el valor de sus bienes asegurados. Produce también en determinados Ramos, muy principalmente en Automóviles, Marítimo y Responsabilidad Civil, una fuerte subida del costo de las indemnizaciones al que hay que hacer frente con primas cobradas con antelación y calculadas para otros valores numéricos.

3. Los tipos de interés, aún en vigor, son anormalmente altos. Siendo la actividad aseguradora en buena parte un negocio financiero, es lógico que la fuerte subida de intereses que hemos conocido durante los últimos años haya sido un elemento que afecte a los niveles de primas; pero no olvidemos que el tipo de prima queda fijo durante la vida del contrato, mientras que los intereses de las reservas pueden sufrir una disminución más rápida. La consecuencia puede ser grave para las compañías aseguradoras.

4. Por último, el progreso tecnológico constante crea también problemas graves. En primer lugar, la rapidez con que se producen estos cambios hace prácticamente imposible disponer de la suficiente base de experiencia y de estadística. Hoy día todas las compañías aseguramos algunas veces, riesgos para los que no se ha podido aún crear la suficiente base técnica para el cálculo de la prima. Por otra parte, es innegable que el campo de Seguro, tanto de Vida como de los Ramos de Seguros Generales, aumenta porque el cambio social y técnico exige nuevas modalidades, a pesar de la escasa creación de riqueza a que hemos aludido.

Los comentarios que anteceden se han hecho pensando exclusivamente en el Seguro Directo, pero en esencia son también aplicables al Reaseguro. Uno no puede vivir sin el otro. Ningún análisis sobre el seguro, por somero y superficial que este sea, puede hacerse sin tener en cuenta, en la circunstancia, el estado del reaseguro. Como se encuentra en el día de hoy este elemento fundamental de nuestra actividad, y qué futuro podemos augurarle son interrogantes de la mayor importancia.

Es un hecho público que los últimos años el reaseguro europeo ha obtenido, en general, resultados técnicos desfavorables y las quejas de las compañías reaseguradores y sus esfuerzos por modificar las condiciones de sus contratos han sido bien evidentes, tanto en las reuniones del ROA (Reinsurance Office Association) y Montecarlo como en todas las negociaciones habidas para las renovaciones. Pero este hecho, con ser importante, no es necesariamente dramático si existen y funcionan los mecanismos que han de restablecer el equilibrio. Nadie debe estar mas interesado que el seguro directo en proteger la solvencia y solidez de las compañías reaseguradoras, puesto que sin ellas todo el sorprendente y caso milagroso mecanismo del seguro se 
hundiría de la noche a la mañana. Pero la realidad es que los mismos elementos que han perturbado el seguro durante los años setenta han influído de forma similar sobre el reaseguro. El reaseguro tradicional se ha visto de súbito acompañado por una numerosa corte de nuevos reaseguradores. La facilidad del acceso al reaseguro es la causante de esta proliferación. Uno de los ejemplos más notables es el cambio experimentado en el Lloyd's of London, donde se ha registrado durante la década de los setenta una verdadera avalancha de nuevos sindicatos reaseguradores. Su exceso de capacidad le ha llevado también a una excesiva competencia ; los altos intereses del dinero a una política de "Cash Flow Underwriting ». Las consecuencias han sido altas tensiones en la relación seguro-reaseguro. Pero en los últimos tiempos ya se aprecia una disminución en la oferta del reaseguro que se hace claramente más selectivo y exigente, que endurece las condiciones técnico-ecónomicas que rigen en los contratos proporcionales. (Técnicas : equilibrio en la capacidad, exclusión de determinada modalidades de cobertura). (Económicas : reducción de depósitos, incremento de intereses sobre los mismos, reducción de comisiones), y una mayor y más detallada información de la cedente al reaseguro sobre los negocios de que se trate. El reaseguro hace hoy lo necesario para rectificar a su favor la situación.

Tan importante como la material y efectiva solidez del reaseguro es otro elemento en el que se basan en la práctica todas la diarias e innumerables operaciones del seguro mundial : la confianza. Ello confiere a los acontecimientos ocurridos en los últimos meses en el mercado británico una especial gravedad.

En resúmen, podemos decir que toda la actividad aseguradora se encuentra navegando en mares agitados.

No obstante, si se analizan los resultados del seguro durante el período de crisis y se los compara con los del sector industrial, es indudable que el seguro da pruebas de una mayor estabilidad en su funcionamiento. Las violentas caídas en las cifras de negocio de muchos tipos de industria no ocurren en el Seguro, simplemente porque la Cartera de seguros ya existentes permanece, mientras que la demanda de un producto industrial puede disminuir y en la práctica así ocurre, en porcentajes dramáticos, y en muy corto período de tiempo. Esta es, a mi juicio, una importante ventaja del negocio asegurador. Pero en modo alguno queremos decir que los efectos de una crisis prolongada no afecten al seguro. Le afectan, y muy seriamente, pero de manera más lenta, más espaciada y que ofrece, por ello, mayores posibilidades de protección.

La crisis económica actual es seguramente la de más larga duración que ha conocido el mundo desarrollado. Son ya nueve años de depresión, de inflación y de paro. Nueve años en que todos los gobiernos occidentales, sin excepción, vienen haciendo dolorosos esfuerzos para curar las raíces del mal.

Es verdad que varios países europeos y los Estados Unidos han conseguido importantes éxitos en la lucha contra la inflación ; pero no así en la lucha contra el paro, ni tampoco han conseguido reavivar la demanda. El número de suspensiones de pago y quiebras continúa en aumento en casi todos los países de Occidente. El peso sobre las economías europeas y de Estados Unidos de las deudas de América latina y países de la cortina de hierro, es enormemente preocupante, y muchos economistas lo ven como una gran avalancha que se acerca y que puede conmover profundamente todo el sistema financiero occidental. 
En esta circunstancias es bien dificil mirar con optimismo el futuro de un sector económico cualquiera. Y claro está que ante el hundimiento de las economías occidentales no habrá para que cansarse en hacer más pronósticos. Pero si todavía creemos que * Dios aprieta pero no ahoga », y que estamos sumidos en una crisis económica, como tanta otras anteriores, ciertamente larga, ciertamente profunda, pero que tendrá un fín, entonces sí es el caso de mirar hacia el futuro y, a mi juicio, las perspectivas para la actividad aseguradora son de una paulatina mejoría durante el resto de esta década.

Pero no podemos olvidar, en definitiva, que las previsiones sobre el seguro han de ser realmente previsiones sobre la economía de producción en general, pués solamente una reactivación económica clara puede ofrecer al seguro nuevos capitales en riesgo. El seguro es un servicio que va adosado a la creación de riqueza, y no puede haber un seguro en verdadera expansión dentro de una economía en crisis. ¿ Cuales son, pués, las perspectivas próximas de las economías occidentales?

Evidentemente aparecen a diario nuevas razones de preocupación. Hoy parece que el descenso de los precios del petróleo, si es rápido y pronunciado, puede traer tantas complicaciones como ocasionó su subida, al disminuir violentamente la solvencia de los países productores y las posibilidades de financiación creadas por el reciclaje de los petrodólares. Pero no puedo dejar de recordar que la economía mundial se encontraba más sana con una energía más barata antes de la crisis del petróleo, y que una rebaja de sus precios, aunque cause cierta extorsión, producirá también efectos positivos para el conjunto. Estamos, pués, en un momento muy incierto. No obstante, hay, a mi juicio, unas razones de optimismo. Como muy principal citaría la evolución de Estados Unidos que muestra, por vez primera, marcados indicios de reactivación. Si esto se confirma la demanda americana es capaz de poner en marcha el resto de las economías occidentales; la inversión y la producción de bienes aumentaría con rapidez, pués hay mucha capacidad disponible y ello traería en consecuencia un mercado de seguros más equilibrado. La reducción de los intereses de las reservas obligaría también a una revisión del nivel de primas, tendiendo a la eliminación del "cash flow underwriting », y a una vuelta a normas de gerencia más tradicionales, con base en cálculos técnicos de siniestralidad y costos de producción.

Quiero creer, pués, que estamos en vísperas de una mejoría de la coyuntura general que tomará tiempo, pero que puede ser el fín de los graves males que nos han empobrecido durante los últimos ocho años. 